\title{
Ablation Therapies in Small Renal Masses
}

\author{
๑ Ekrem Güner MD1, ๑ Osman Özdemir MD¹, ๑ Fatma Aysun Erbahçeci MD² \\ 1 University of Health Sciences, Bakırköy Dr. Sadi Konuk Training and Research Hospital, Clinic of Urology, Istanbul, Turkey \\ 2 University of Health Sciences, Bakırköy Dr. Sadi Konuk Training and Research Hospital, Clinic of Interventional Radiology, Istanbul, Turkey
}

\begin{abstract}
Small renal masses are defined as renal neoplasms with the largest diameter less than $4 \mathrm{~cm}$ and the incidence of renal malignancies is increased with the widespread use of cross-sectional imaging methods. One of the options for disease management in small renal masses is ablation therapy. Ablation therapies include options such as radiofrequency ablation, cryoablation and irreversible electroporation. In this review, outcomes and comparisons of ablation therapies used in small renal masses are discussed together with current approaches and studies.

Keywords: Ablation, small renal mass, radiofrequency ablation, cryotherapy
\end{abstract}

\section{Introduction}

Small renal masses are defined as renal neoplasms with the largest diameter less than $4 \mathrm{~cm}$ and they express $\mathrm{T} 1 \mathrm{a}$ tumors in tumor, nodes, metastases (TNM) staging (1). Today, with the widespread use of cross-sectional imaging methods, the majority of renal masses are incidentally detected. As a result, the incidence of primary renal malignancies increases over the years (2). There is a wide range of options from active followup to radical nephrectomy in the management of small renal masses. One of these options is ablation therapy. According to the American Urological Association (AUA) guidelines, the gold standard treatment for T1a renal masses is partial nephrectomy, and ablation therapies are offered as treatment options (3).

In this review, outcomes and comparisons of ablation therapies used in small renal masses are discussed together with current approaches and studies.

\section{Patient Selection}

As with all treatment options, the most important point in the planning of ablation therapy is the selection of the appropriate patient. Ablative therapies are a good option, especially in patients with contraindicated surgical treatment, patients with severe comorbidities, or those who do not consent surgery (4). In addition, it may be considered as a treatment method in patients with conditions such as solitary kidney, transplanted kidney, underlying renal failure, multiple renal tumors, and recurrent tumor in the nephrectomy bed (5).

\section{Basic Information about Ablation Therapies}

Ablation therapy in patients with small renal masses should be performed only in cases where the treatment of the whole lesion is technically feasible and renal biopsy is required before the procedure (6).

Tumor ablation is essentially the process of causing necrosis of tumor cells by energy transfer to the target with the help of imaging. These energy sources are roughly divided into thermal and non-thermal sources. Radiofrequency ablation (RFA) that provides high-temperature necrosis of tumor cells and cryotherapy method that provides freezing necrosis of the cells can be cited as examples of thermal ablation. Electroporation, which causes cell death by causing permanent pores in the cell membrane, is an example for non-thermal ablation $(7,8)$.

Among the ablation therapies, thermal ablation methods are used more commonly and the most prominent methods are RFA and cryotherapy.

\section{Ablation Methods \\ Radiofrequency Ablation \\ RFA is based on the generation of heat by means of an alternating electric current used at different frequencies and consequently cell death occurs in the exposed area (9). This alternating electric current is transferred to the tissue with the aid of a probe placed in the center of the target tissue, and these systems are generally monopolar.}


RFA-induced cellular damage is based on a time-temperature curve where less time is required at higher temperatures (9). In a study, cellular damage was shown to develop after 60 minutes exposure to $45^{\circ} \mathrm{C}, 5$ minutes exposure to $55^{\circ} \mathrm{C}$, and 1 -minute exposure to $70^{\circ} \mathrm{C}(10)$. When the temperature exceeds $60^{\circ} \mathrm{C}$, the cell loses its intracellular buffering ability, thereby increasing intracellular calcium levels, resulting in cellular death. Subsequently, acidosis and coagulation necrosis develop with increasing local inflammation (11).

In thermal ablation, cellular damage develops in different phases according to temperature rise. At temperatures of $50-80^{\circ} \mathrm{C}$, coagulation and cellular damage due to protein denaturation develops within seconds or minutes. Tissue ablation is observed with dehydration and vacuolization at temperatures above $100^{\circ} \mathrm{C}$, while carbonization and melting are finally observed in the tissue when $150-300^{\circ} \mathrm{C}$ is reached (9).

Although there is no definite consensus on this issue in the literature, it is stated that it is necessary to reach a temperature of at least $60^{\circ} \mathrm{C}$ for irreversible cellular damage and necrosis (9). In another publication, it is reported that at least $70^{\circ} \mathrm{C}$ temperature should be reached (4). It has also been reported that better and more effective cellular death can be achieved with two cycles of active ablation phase with a short-term cooling phase between them (12).

\section{Cryoablation}

Cryotherapy is another method of thermal ablation, which uses freezing temperatures instead of extremely high temperatures. It is known that the first modern cryotherapy probes worked with liquid nitrogen in the 1960s, followed by the more effective argon gas-based probes (4).

In animal models, tissue has been shown to be destroyed by cryoablation at temperatures between $-19.4^{\circ} \mathrm{C}$ and $-50^{\circ} \mathrm{C}$. In cancer tissues, it is stated that the target temperature should be $-40^{\circ} \mathrm{C}$ to ensure cellular death (4).

Larger areas of cellular necrosis have been reported to occur with multiple freezing and thawing cycles rather than a onetime freezing. It is stated that the risk of bleeding increases if the duration of the freezing cycle is 5 minutes, and the risk of tumor breakage increases when it is 15 minutes. Therefore, it was concluded that the ideal period of freezing should be between 8-10 minutes $(13,14)$.

Similar to RFA, two cycles of freezing and thawing are applied in cryoablation to ensure that cellular death is more effective (4).

\section{Application Methods in Ablation Therapies: Laparoscopic and Percutaneous Approaches}

Ablation treatments can be performed by laparoscopic or percutaneous approach. The most important factor in choosing the method is the location of the tumor. Percutaneous approach is ideal for lateral and posterior tumors that are further away from vital organs. Laparoscopic method is more suitable for anterior tumors, especially because it allows dominating the surrounding anatomy (9). However, RFA is often performed with a percutaneous approach, whereas cryoablation is usually performed laparoscopically (4).
During percutaneous application of RFA, methods such as ultrasound, CT, CT fluoroscopy, MRI can be used for guiding and placement of the needle.

In a meta-analysis comparing percutaneous and surgical methods for renal tumor ablation, a total of 46 cases were included in the study, and 28 of them underwent percutaneous ablation. In 28 case series with percutaneous approach, RFA was reported as ablative therapy in 21 patients and cryotherapy was reported in only seven patients. Regarding 18 patients with surgical approach, only three patients underwent RFA and cryotherapy was performed in 15 cases (15).

According to many studies in the literature, when the percutaneous or laparoscopic thermal ablation procedures were compared, similar results were found at both primary endpoints. No significant difference was observed in primary efficacy, disease-specific survival and complication rates $(16,17,18)$. In contrast, in a meta-analysis, the primary efficacy of the percutaneous approach was reported to be significantly lower than that of the surgical approach ( $87 \%$ vs $94 \%$ ). There was no significant difference in secondary efficacy. In the same metaanalysis, the rate of major complications was reported to be significantly lower in the percutaneous approach than in the surgical approach (3.1\% vs $74 \%)$ (15).

\section{Outcomes of Ablative Treatments}

Currently, there are no randomized controlled trials comparing ablation and surgical treatments. Most of these publications are retrospective or observational studies. According to current guidelines, the gold standard in small renal masses is reported as partial nephrectomy (19). According to European guidelines, ablation therapies in small renal masses are recommended in cases where the patient is not suitable for surgical treatment and has a multifocal malignant tumor as mentioned above in the patient selection section $(7,20)$.

According to a recent meta-analysis comparing treatments in renal tumors less than $7 \mathrm{~cm}, 5$-year cancer-specific survival and metastasis-free survival were reported to be similar between partial nephrectomy and thermal ablation (21). In contrast, in another meta-analysis, laparoscopic cryoablation was compared with laparoscopic and robotic partial nephrectomy, where it was shown that there was a significantly higher risk of local recurrence and metastasis in the cryoablation group (22).

Ablation treatments have been reported to be less invasive, less associated with perioperative complications, cause less blood loss and shorter hospital stay than surgical treatments. In addition, renal function loss and the cost of the procedure are also reported to be less than surgery $(4,7)$. In addition to these, ablation therapies are appealing treatment modalities in suitable patients with other advantages such as the fact that it is a procedure that usually requires a day or overnight stay and can be applied more safely than the surgery, especially in patients with high comorbidities.

There is no randomized controlled trial comparing ablation treatments and surgical treatments, nor is there a randomized controlled clinical trial comparing these two basic ablation methods. Most publications in the literature are retrospective and include a small number of patients. In the UK, both 
cryotherapy and RFA are recommended for small renal masses according to NICE (National Institute for Health and Care Excellence) guidelines (23).

According to a meta-analysis in 2008 , local recurrence was found to be higher in RFA compared to cryoablation and it was stated that the need for a second ablation was higher in RFA (24). Another meta-analysis involving 20 cryoablation and 11 RFA case series was published in 2012. In this metaanalysis published by El Dib et al. (24), 457 patients undergoing cryoablation and 426 patients undergoing RFA were studied. The mean tumor size was $2.5 \mathrm{~cm}$ in the cryoablation group and $2.7 \mathrm{~cm}$ in the RFA group. Among the cryotherapy group, the surgical method was laparoscopic in 13 of the 20-case series, percutaneous in six and conventional in one. In 11 studies in the RFA group, seven were reported to be performed percutaneously, one by laparoscopy, and three by both. In this meta-analysis, the clinical efficacy of cryotherapy in 457 patients was found to be $89 \%$. The clinical efficacy of RFA in 426 patients was reported to be $90 \%$. According to these data, similar oncologic and clinical outcomes have been reported in both treatment modalities (25). In a more recent observational study, cryotherapy has been reported to have superior outcomes compared to RFA in metastasis-free survival. In the same study, no significant difference was found between the two groups in local recurrence-free survival (26).

The rate of renal function preservation in the kidney after any surgical treatment is directly related to the remaining renal volume after the procedure. Since normal renal parenchymal loss is minimal in ablative therapies, long-term renal functions are better than surgical treatments (27). In a study comparing renal functions after cryoablation, RFA and partial nephrectomy, it was reported that both renal parenchymal volume and glomerular filtration rate decreased significantly in partial nephrectomy compared to ablation methods. In the same study, no difference was found between the two ablation methods (28).

The most common complications in ablative treatments are bleeding and post-ablation hemorrhage. Since radiofrequency ablation already involves high temperatures, hemorrhage is less common and hemorrhage occurs more often after cryotherapy. In addition, ureteral or renal pelvic injuries are rarely seen. If thermal ablation extends beyond the target tissue and reaches the collecting system, urine leakage may be observed. More rarely, bowel injury, seeding in the treatment tract and pneumothorax may be observed (risk $<0.01 \%)(9)$. According to a meta-analysis, the complication rate was $19.9 \%$ in cryotherapy patients and $19 \%$ in the RFA group. It has been concluded that there are similar results between the two treatment methods in terms of complication rates (25).

\section{Follow-up after Ablative Therapy}

The success of the treatment after ablation is determined by radiological findings. The absence of contrast enhancement in tumor tissue and the cessation of tumor growth (MRI or CT) at 3 months after the procedure are evaluated as successful ablation (29). According to the AUA guidelines, it is recommended that the patient be followed up by cross-sectional imaging at 3 and 6 months after ablation and annually for 5 years thereafter (30).

\section{Other Methods in Ablation Therapies}

In addition to RFA and cryoablation, different ablation methods are available. Microwave ablation, high intensity focused ultrasound (HIFU) and irreversible electroporation are examples.

\section{Microwave Ablation}

Microwave ablation is based on high temperature production similar to RFA. With the help of probes, electromagnetic energy is transferred to the tumor tissue at frequencies between 900 Mhz and $2.5 \mathrm{GHz}$ and consequently high temperatures leading to coagulation necrosis and cell death are obtained (10). Results have been reported that microwave ablation can achieve higher temperatures, higher volume ablation and shorter treatment time than RFA (10).

There are several studies on the results of microwave ablation. In a study of the results of 12 patients who underwent percutaneous microwave ablation, no residual tumor or recurrence was reported during the median follow-up period of 11 months (31). In a randomized prospective study of 102 patients, Guan et al. (31) compared microwave ablation and partial nephrectomy, and reported that estimated blood loss, complication and renal function loss were significantly better in microwave ablation. In another report, the results of 10 patients who underwent laparoscopic microwave ablation were examined and a high recurrence rate of $38 \%$ was found (32).

Variable results with microwave ablation are available and larger, randomized controlled trials are needed.

\section{HIFU (High Intensity Focused Ultrasound)}

HIFU is based on high heat generation by sending high intensity ultrasound waves to the target tissue. As in other ablation methods, coagulation necrosis in tumor cells is created by this high energy in HIFU. The major advantage of HIFU over other methods is that it is completely noninvasive, but its oncologic results are not optimal (4).

\section{Irreversible Electroporation}

Unlike other ablation methods, irreversible electroporation is a non-thermal ablation method and no temperature is used for this procedure. Instead, electrical currents are sent to the cell membranes to form pores in the membrane. As a result, cell homeostasis deteriorates and cellular death occurs (10).

Muscle contractions and severe arrhythmias due to the energy currents applied in electroporation have been reported to increase concerns in this approach (27). There are few reports on the efficacy and safety of electroporation and large series of randomized trials are needed.

\section{Conclusion}

There are various ablation methods, including thermal and nonthermal. Ablation therapies have been found to be preferred in the appropriate patient group because of their satisfactory oncologic outcomes, short hospital stay and low complication rates in small renal masses.

\section{Ethics}

Peer-review: Internally peer-reviewed. 


\section{Authorship Contributions}

Concept: E.G., O.Ö., F.A.E., Design: E.G., O.Ö., F.A.E., Data Collection or Processing: E.G., O.Ö., F.A.E., Analysis or Interpretation: E.G., O.Ö., F.A.E., Literature Search: E.G., O.Ö., F.A.E., Writing: E.G., O.Ö., F.A.E.

Conflict of Interest: No conflict of interest was declared by the authors.

Financial Disclosure: The authors declared that this study received no financial support.

\section{References}

1. Gill IS, Aron M, Gervais DA, Jewett MA. Clinical practice. Small renal mass. N Engl J Med 2010;362:624-634.

2. Almassi N, Gill BC, Rini B, Fareed K. Management of the small renal mass. Transl Androl Urol 2017;6:923-930.

3. Bandi G, Hedican S, Moon T, et al. Comparison of postoperative pain, convalescence, and patient satisfaction after laparoscopic and percutaneous ablation of small renal masses. J Endourol 2008;22:963-967.

4. 4.Taylor BL, Stavropoulos SW, Guzzo TJ. Ablative Therapy for Small Renal Masses. Urol Clin North Am 2017;444:223-231.

5. Zargar H, Atwell TD, Cadeddu JA, et al. Cryoablation for small renal masses: selection criteria, complications, and functional and oncologic results. Eur Urol 2016;69:116-128.

6. Finelli $A$, Ismaila $N$, Bro $B$, et al. Management of small renal masses: American Society of Clinical Oncology Clinical Practice Guideline. J Clin Oncol 2017;35:668-680.

7. Withington J, Neves JB, Barod R. Surgical and Minimally Invasive Therapies for the Management of the Small Renal Mass. Curr Urol Rep 2017;18:61.

8. Brace C. Thermal tumor ablation in clinical use. IEEE Pulse 2011;2:28-38.

9. Kelly EF, Leveillee RJ. Image guided radiofrequency ablation for small renal masses. Int J Surg 2016;36:525-532.

10. Castro A Jr, Jenkins LC, Salas N, et al. Ablative therapies for small renal tumours. Nat Rev Urol 2013;10:284-291.

11. Glamore M, Leveillee R. CT-guided renal ablation. In: Liao JC, Su L, eds. Advances in image- guided urologic surgery. New York, Springer, 2015; 175-184.

12. Park S, Anderson JK, Matsumoto ED, et al. Radiofrequency ablation of renal tumors: intermediate-term results. J Endourol 2006;20:569-573.

13. Auge BK, Santa-Cruz RW, Polascik TJ. Effect of freeze time during renal cryoablation: a swine model. J Endourol 2006;20:1101-1105.

14. Breen DJ, Bryant TJ, Abbas A, et al. Percutaneous cryoablation of renal tumours: outcomes from 171 tumours in 147 patients. BJU Int 2013; 112:758-765.

15. Hui GC, Tuncali K, Tatli S, et al. Comparison of percutaneous and surgical approaches to renal tumor ablation: metaanalysis of effectiveness and complication rates. I Vasc Interv Radiol 2008;19:1311-1320.
16. Hinshaw JL, Shadid AM, Nakada SY, et al. Comparison of percutaneous and laparoscopic cryoablation for the treatment of solid renal masses. AJR Am J Roentgenol 2008;191:1159-1168.

17. Sisul DM, Liss MA, Palazzi KL, et al. RENAL nephrometry score is associated with complications after renal cryoablation: a multicenter analysis. Urology 2013;81:775-780.

18. Zargar H, Samarasekera D, Khalifeh A, et al. Laparoscopic vs percutaneous cryoablation for the small renal mass: 15-year experience at a single center. Urology 2015;85:850-855.

19. Ljungberg $B$, Bensalah $K$, Canfield $S$, et al. EAU guidelines on renal cell carcinoma: 2014 update. Eur Urol 2015;67:913-924.

20. Pierorazio PM, Johnson MH, Patel HD, et al. Management of renal masses and localized renal cancer: systematic review and metaanalysis. J Urol 2016;196:989-999.

21. Klatte T, Shariat SF, Remzi M. Systematic review and meta-analysis of perioperative and oncologic outcomes of laparoscopic cryoablation versus laparoscopic partial nephrectomy for the treatment of small renal tumors. J Urol 2014;191:1209-1217.

22. NICE Guidance IPG353-percutaneous radiofrequency ablation for renal cancer. https://www.nice.org.uk/guidance/ipg353/chapter/1 guidance. Accessed March 2017

23. Kunkle DA, Uzzo RG. Cryoablation or radiofre- quency ablation of the small renal mass a meta-analysis. Cancer 2008;113:2671-2680.

24. El Dib R, Touma NJ, Kapoor A. Cryoablation vs radiofrequency ablation for the treatment of renal cell carcinoma: a meta-analysis of case series studies. BJU Int 2012;110:510-516.

25. Thompson RH, Atwell T, Schmit G, et al. Comparison of partial nephrectomy and percutaneous ablation for $\mathrm{CT} 1$ renal masses. Eur Urol 2015;67:252-259.

26. Kavoussi N, Canvasser N, Caddedu J. Curr Urol Rep 2016;17:59.

27. Woldu SL, Thoreson GR, Okhunov Z, et al. Comparison of renal parenchymal volume preservation between partial nephrectomy, cryoablation, and radiofrequency ablation using 3D volume measurements. J Endourol 2015;29:948-955.

28. Ahmed $\mathrm{M}$, Solbiati L, Brace $\mathrm{CL}$, et al. Image-guided tumor ablation: standardization of terminology and reporting criteria--a 10-year update. J Vasc Interv Radiol 2014;25:1691-1705.

29. Donat SM, Diaz M, Bishoff JT, et al. Follow-up for clinically localized renal neoplasms: AUA guideline. J Urol 2013;190:407-416.

30. Liang P, Wang Y, Zhang D, et al. Ultrasound guided percutaneous microwave ablation for small renal cancer: initial experience. J Urol 2008; 180:844-848.

31. Guan W, Bai J, Liu J, et al. Microwave ablation versus partial nephrectomy for small renal tumors: Intermediate-term results. I Surg Oncol 2012;106:316-321.

32. Castle SM, Salas N, Leveillee RJ. Initial experience using microwave ablation therapy for renal tumor treatment: 18-month follow-up. Urology 2011;77:792-797. 